\title{
Erratum
}

\section{TYPES OF MARRIAGES, POPULATION STRUCTURE AND GENETIC DISEASE - Erratum}

\author{
T. M. B. MACHADO, T. F. BOMFIM, L. V. SOUZA, N. SOARES, \\ F. L. SANTOS, A. X. ACOSTA AND K. ABE-SANDES
}

Some errors in the calculation of coefficient of inbreeding $(F)$ and mean coefficient of inbreeding $(\alpha)$ values were detected in this article and have been re-calculated.

Page 3, Methods, paragraph 3, should read:

A coefficient of inbreeding $(F)$ was calculated for each couple and mean coefficients of inbreeding $(\alpha)$ for the population then analysed for each period (Freire-Maia, 1974). Consanguineous marriages were classified according to the degree of relationship between spouses, i.e. double first cousins $(F=1 / 8)$, first cousins $(F=1 / 16)$, first cousin once removed $(F=1 / 32)$, second cousins $(F=1 / 64)$, second cousin once removed $(F=1 / 128)$ and third cousins $(F=1 / 256)$ (Lancaster, 2007). For all individuals and couples whose degree of inbreeding was not specified the value of $F$ was taken to be $1 / 16$, because since 1983 the dispensation requirement for marriage has been a 4th grade civil relationship, i.e. first cousins. All of the recorded degrees of consanguinity were converted from canonical to civil nomenclature.

Page 4, Results, paragraph 3, should read:

The values of $F$ ranged from 0.000703 to 0.085508 per year, and the mean coefficient of inbreeding $(\alpha)$ was 0.014530 .

Page 5, Results, paragraph 2, should read:

The values of $F$ ranged from 0.000125 to 0.087281 . The highest $F$ value was in 1951 when $99.4 \%$ of marriages were endogamic, and $24.2 \%$ of these marriages were consanguineous. The mean coefficient of inbreeding $(\alpha)$ for the 2 nd study period was 0.005670 .

Page 6, Results, paragraph 2, should read:

In this period, the frequency of consanguineous marriage was $4.2 \%$. The average $F$ value was 0.001674 and ranged from 0.000250 to 0.098562 per year.

Page 10, new reference:

Lancaster, F. M. (2007) Genetic and Quantitative Aspects of Genealogy. URL: http://www. genetic-genealogy.co.uk/index.html

\section{References}

Machado, T. M. B., Bomfim, T. F., Souza, L. V., Soares, N., Santos, F. L., Acosta A. X. \& Abe-Sandes K. (2012) Types of marriages, population structure and genetic disease. Journal of Biosocial Science published online 25 October 2012, doi: 10.1017/S0021932012000673 